\title{
Rajae Benchemsi, La controverse des temps
}

\section{Paola Martini}

\section{(2) OpenEdition}

\section{Journals}

\section{Edizione digitale}

URL: http://journals.openedition.org/studifrancesi/9690

DOI: 10.4000/studifrancesi.9690

ISSN: 2427-5856

\section{Editore}

Rosenberg \& Sellier

\section{Edizione cartacea}

Data di pubblicazione: 1 décembre 2007

Paginazione: 701

ISSN: 0039-2944

Notizia bibliografica digitale

Paola Martini, «Rajae Benchemsi, La controverse des temps», Studi Francesi [Online], 153 (LI | III) | 2007, online dal 30 novembre 2015, consultato il 11 janvier 2021. URL: http://journals.openedition.org/ studifrancesi/9690 ; DOI: https://doi.org/10.4000/studifrancesi.9690

Questo documento è stato generato automaticamente il 11 janvier 2021.

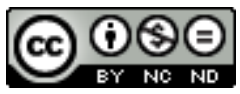

Studi Francesi è distribuita con Licenza Creative Commons Attribuzione - Non commerciale - Non opere derivate 4.0 Internazionale. 


\title{
Rajae Benchemsi, La controverse des temps
}

\author{
Paola Martini
}

\section{NOTIZIA}

RAJAE BENCHEMSI, La controverse des temps, Paris, Wespieser, 2006, pp. 233.

Rajae Benchemsi, autrice di poesie e racconti, dal 2003 si è cimentata anche nel genere romanzesco ottenendo con Marrakech, lumière d'exil un buon successo di critica, tanto che la casa editrice Wespieser ha deciso di sostenere anche l'ultima fatica letteraria della scrittrice marocchina, La controverse des temps. Il romanzo si apre su un dibattito storico-filosofico che accende la disputa in un gruppo di amici in visita alle prigioni sotterranee del Moulay Ismail: invece di considerare, sulla falsa riga delle cronache tramandate dai monaci cristiani, il sultano alawita Ismail un barbaro sanguinario, non sarebbe opportuno riconoscere nella sua figura uno dei pochi uomini capace di tener testa alle mire espansionistiche di Luigi XIV, nonché uno dei personaggi fondamentali della storia del Marocco?

2 Najia, storica interessata alla monarchia, nonché voce narrante, contrariamente all'opinione della maggior parte dei membri della comitiva, è persuasa della grandezza del Moulay Ismaill: per lei il sultano è stato troppo a lungo vittima di un'impostura storica che ha impedito la ricostruzione di un passato basata su un'osservazione razionale e imparziale dei fatti. Il confronto sull'argomento prosegue in un salotto dell'alta borghesia di Casablanca, un vero e proprio microcosmo che offre alla scrittrice l'occasione per tracciare un affresco della società marocchina, attualmente incapace di godere pienamente della propria eredità millenaria perché proiettata in modo acritico verso modelli culturali occidentali. L'appuntamento mondano diventa anche la cornice del folgorante incontro tra Houda, giovane filosofa atea, e Ilyas, esperto di mistica islamica. L'intesa è reciproca, ma l'amore è impossibile: Houda ha un approccio laico alla vita e non riesce a vedere un reale ostacolo alla possibilità di vivere la loro 
passione, mentre Ilyas, peraltro già sposato, non potrebbe mai venir meno al proprio impegno spirituale.

3 I personaggi appaiono fin dall'inizio inafferrabili e mutevoli nelle loro contraddizioni, eccellente radiografia di una classe intellettuale alla ricerca della propria identità e di una via che possa conciliare la tradizione e la riscoperta del proprio passato ancestrale con una visione più aperta e moderna della società e dei rapporti che la regolano. 